\title{
LITERATURA
}

\section{Tendências para a literatura}

A renovação da literatura é um processo lento, que ocorre por movimentos nem sempre visíveis e lineares. 0 cenário atual é de grande dispersão, com obras que se destacam mais pelas características do autor do que por sua filiação a uma escola ou corrente. Neste ensaio, José Castello, escritor e colaborador da Revista Bravo!, observa que a pluralidade e a diversidade, assim como a aproximação da vida cotidiana, são algumas tendências fortes da literatura nos próximos anos.

xiste uma interessante agitação, um estado de efervescência na literatura contemporânea. Talvez não tenha surgido ainda um grupo, ou pelo menos um punhado de nomes, que possa delimitar, com visibilidade, esse novo momento. Talvez ele ainda seja obscuro, ou silencioso, o que não quer dizer que não exista. No cenário bra- sileiro, afora os nomes de Bernardo Carvalho, 44 anos, com um romance como Nove noites, na prosa, e de Fabrício Carpinejar, 32 anos, e Paulo Henriques Brito, 53 anos, respectivamente com Cinco Marias e M acau, na poesia, que hoje despertam respeito mesmo entre aqueles que não chegam a se entusiasmar com seus livros, o que há é uma produção ainda tímida, não muito visível. Mas na qual já se podem antever bons pedaços do futuro.

Não é uma questão de geração: as idades variam e as procedências, mais ainda. É al go que se passa no texto. $\mathrm{Na}$ prosa brasileira, apesar do modismo duvidoso do neobarroco e das experiências pouco estimulantes do novo rea- 
lismo, ninguém pode negar o talento de escritores como Luiz Ruffato, Joca Reiners Terron, Michel Laub, Cíntia Moscovich, Altair Martins, Rubens Figueiredo, Lívia Garcia-Rosa e Marce lo Benvenutti. Na poesia, ainda hoje muito devastada pela influência formalista, a atenção deve ser voltada para nomes como Lucinda Persona, Mauricio Arruda Mendonça, Contador Borges, Dora Ferreira e Jussara Salazar. 0 que os une? Nada. Isso é ruim? Parece que não. Ao contrário, antes de ser um sintoma de debilidade, essa dissipação indica o valor emprestado à voz própria e ao olhar pessoal sobre o mundo, que vem sempre acima de cânones, escolas, manifestos ou modismos. É dessa dispersão fértil que surgem as melhores coisas.

Em Portugal . A renovação na literatura é lenta, se dá em movimentos nem sempre perceptíveis, passa por falsos rumores, falsos prestígios e falsas expectativas. Em Portugal, por exemplo, ela está no que pode ser visto, aparentemente, como um passo para trás - uma volta ao intimismo e ao lirismo. Autor de Baía dos tigres, 0 prosador Pedro Rosa Mendes, de 34 anos, que já está traduzido em mais de 20 países, veio do jornalismo. Baía faz - exatamente como o jornalismo uma mistura de gêneros, mesclando textos que vão da entrevista à poesia, com o objetivo de narrar uma viagem através da África.

Uma tendência? Não tenhamos tanta pressa. Outro prosador português, José Luís Peixoto, de 30 anos, também vindo da imprensa, faz, por exemplo, um uso bem diferente dela. Na prosa poética M orreste-me, ele trabalha sobre um tema íntimo: a morte do pai. Em Nenhum olhar, exercita uma prosa melancólica. Peixoto também é poeta, de versos livres elongos, e antimodernos, como os de A criança em ruínas. Em Portugal, quando se fala de renovação, não se pode esquecer o nome de Possidônio Cachapa, e livros como Viagem ao coração dos pássaros e Segura-te ao meu peito em chamas, não é preciso dizer, trabalham com o lirismo e o romantismo. Cachapa já declarou, mais de uma vez, que segue as lições de Florbela Espanca, que sempre escrevia conectada "ao astro que flameja". Talvez seja essa idéia de Florbela o único fio verdadeiro a ligá-los.

\section{Nomundo hispano-americano.} A diversificação - a pluralidade- étambém uma tônica da literatura hispanoamericana de hoje, e por isso ela atravessa uma fase de menor visibilidade. Um dos grandes talentos em ascendência é, sem qualquer dúvida, 0 argentino Alan Pauls, cujo terceiro romance, Wasabi, já foi traduzido no Brasil pela Iluminuras. O quarto, El pasado ("O
No cenário brasileiro, o que há é uma produção ainda tímida, não muito visível. Mas na qual já se podem antever bons pedaços do futuro. passado"), saiu recentemente na Espanha e vem recebendo, desde então, críticas entusiasmadas. Na literatura peruana, afirma-se o nomedeSantiago Roncagliolo, um jovem jornalista e roteirista de cinema de 30 anos, autor de Pudor, romance ambientado no rio Amazonas. "Eletraz claridadee profundidade - duas qualidades que raramente encontramos juntas", escreveu o jornal La Razón. Entre seus personagens, estão um homem que se prepara para morrer, uma mulher que coleciona anônimos pornográficos e um menino que vê cadáveres. Há resíduos, tardios, do realismo mágico, mas eles são apenas isso: restos.

Falar de geração é sempre problemático e de eficácia duvidosa. Parece mais da alçada do cadastro civil que da literatura. Por isso, ao lado de um jovem como o peruano Roncagliolo, podemos incluir o boliviano Juan Claudio Lechín, 20 anos mais velho queele. Com o seu La gula del picaflor ("A gula do beija-flor"), que recebeu o prêmio Alfaguara deromance de 2003, eleveio afirmar uma literatura que, como em Pudor, se volta para os temas "menores" da sexualidade e da intimidade no caso, um grupo de obedientes discípulos de Casanova. Um venerável ancião, que foi um célebre sedutor, reúneem um hotel de La Paz um grupo de sete convidados. Eles têm uma única missão: narrar-Ihesuas aventuras amorosas. Para não esquecer a poesia, devemos citar ainda novos poetas chilenos, como Armando Roa Vial, ganhador do prêmio Neruda, e Francisco Véjar, nomes que reafirmam, no país, a precedência da poesia sobre a prosa. 
Pela Europa afora. A busca detendências esbarra, em geral, na simplificação. E aí só se encontra o quesequer. Bem, a pasteurização existe. $\mathrm{Na}$ França, por exemplo, como já mostrou Daniel Lindenberg no livro Rappel à I'ordre ("Chamado à ordem"), o cenário cultural está, em geral, dominado pelo que ele chama de "novos reacionários". Essa guinada à direita estaria, na literatura, representada por autores de prestígio como Michel Houellebecq - o mais estridente e competente deles - e Renaud Camus, Maurice Dantec e Philippe Muray. Na verdade, como já mostrou a prestigiada revista Lire, o que ocorre na França - e em geral na Europa, podemos pensar - é uma espécie de "era da abundância", em quea quantidade predomina sobre a qualidade. $\mathrm{N}$ ão se poderá dizer o mesmo, nas devidas proporções, em relação ao mercado editorial brasileiro? Os lançamentos se multiplicam, numa velocidade atroz. $\mathrm{N}$ em mesmo a imprensa literária consegue acompanhar a enxurrada de títulos novos. A qualidade? Já não se pode medi-la com a mesma segurança.

Bem ao lado, na Espanha - país ainda hoje dominado pelas figuras im-

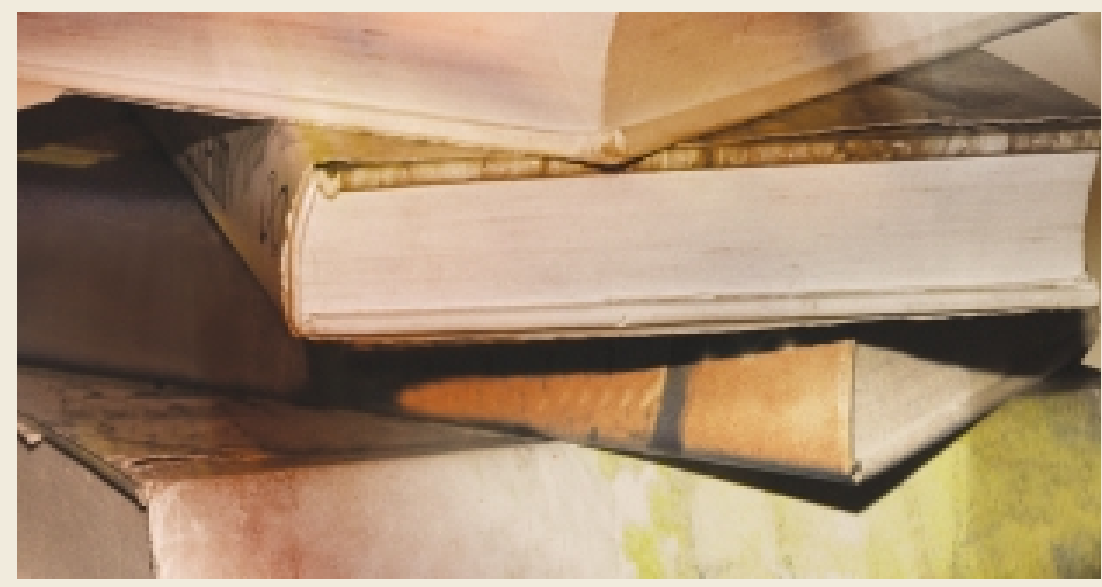

ponentes de Javier Marías e Enrique Villa-Matas, os dois mais importantes autores de língua espanhola na atual idade -, outros nomes, menos festejados, ganham reputação. É o caso da jornalista de EI País Rosa M ontero, que veio recentemente ao Brasil lançar a tradução de seu A louca da casa, um delicado e inspirado livro de gênero absolutamente híbrido. 0 título se refere a uma frase de Santa Teresa de Jesus. A imaginação é a louca da casa. Numa época em que, em todo mundo, há uma volta meio cega à realidade e à superfície, a frase de Santa Teresa parece muito adequada.

$\mathrm{Na}$ Inglaterra, entre os mais jovens, ganham destaque nomes como os de Siddharth Dhanvant Shanghvi, de 26 anos, nascido em Mombai (antiga Bombaim), cujo primeiro livro, A menina que caminhava sobre a água,

Em um mundo devassado e unificado, em que tudo está exposto e tudo se vê, a literatura se interessa pela surpresa, pelo susto, pelo exótico. Mas, no fim das contas, é na realidade mais cotidiana que ela vai encontrá-lo.

narrativa de forte erotismo, foi sucesso não só em Londres, mas nos EUA e na Índia. Outro sucesso de vendas e de crítica é Zadie Smith, de quem já podemos ler, em português, o romance $D$ entes brancos, que já vendeu 1,5 milhão de exemplares só em língua inglesa. No caso deZadie, quetematiza a migração e a discriminação, a literatura está, mais quenunca, ligada, agarrada mesmo, à realidade.

A realidade como objeto primeiro da literatura - e aí podemos pensar tanto na jornalista e escritora austríaca Mariët Meester, de 46 anos, que em um de seus romances faz o relato de uma viagem entre os ciganos da Romênia, como naturca Asli Erdogan, uma escritora de 37 anos, que sobrevive como redatora da revista geográfica Atlas. A realidade, sim, mas como mistério que nunca se deixa decifrar. Basta pensar em Villa-Matas, ou no norte-americano Paul Auster, ou no brasileiro Bernardo Carvalho. Em um mundo devassado e unificado, em que tudo está exposto e tudo se vê, a literatura se interessa pela surpresa, pelo susto, pelo exótico. Mas, no fim das contas, é na realidade mais cotidiana que ela vai encontrá-lo.

José Castello

Colaborador da revista Bravo!

E-mail: josecastello@sulbbs.com 